\title{
Temperature-Dependent Optical Properties of Graphene on Si and $\mathrm{SiO}_{2} / \mathrm{Si}$ Substrates
}

\author{
Sisi Wu ${ }^{1}$, Lingyu Wan ${ }^{1, * \mathbb{D}}$, Liangmin Wei ${ }^{1}$, Devki N. Talwar ${ }^{2} \mathbb{D}$, Kaiyan He ${ }^{1}$ and $_{\text {Zhechuan Feng }}{ }^{1} \mathbb{D}$ \\ 1 Center on Nanoenergy Research, Laboratory of Optoelectronic Materials \& Detection Technology, \\ Guangxi Key Laboratory for the Relativistic Astrophysics, School of Physical Science \& Technology, \\ Guangxi University, Nanning 530004, China; 1907301087@st.gxu.edu.cn (S.W.); lmwei19@163.com (L.W.); \\ gredhky@gxu.edu.cn (K.H.); fengzc@gxu.edu.cn (Z.F.) \\ 2 Department of Physics, University of North Florida, Jacksonville, FL 32224, USA; d.talwar@unf.edu \\ * Correspondence: LYW2017@gxu.edu.cn
}

check for updates

Citation: Wu, S.; Wan, L.; Wei, L.;

Talwar, D.N.; He, K.; Feng, Z.

Temperature-Dependent Optical Properties of Graphene on $\mathrm{Si}$ and $\mathrm{SiO}_{2} / \mathrm{Si}$ Substrates. Crystals 2021, 11, 358. https://doi.org/10.3390/ cryst 11040358

Academic Editor: Giuseppe Prestopino

Received: 7 February 2021

Accepted: 26 March 2021

Published: 29 March 2021

Publisher's Note: MDPI stays neutral with regard to jurisdictional claims in published maps and institutional affiliations.

Copyright: (c) 2021 by the authors. Licensee MDPI, Basel, Switzerland. This article is an open access article distributed under the terms and conditions of the Creative Commons Attribution (CC BY) license (https:// creativecommons.org/licenses/by/ $4.0 /)$.

\begin{abstract}
Systematic investigations are performed to understand the temperature-dependent optical properties of graphene on $\mathrm{Si}$ and $\mathrm{SiO}_{2} / \mathrm{Si}$ substrates by using a variable angle spectroscopic ellipsometry. The optical constants of graphene have revealed changes with the substrate and temperature. While the optical refractive index (n) of monolayer graphene on Si exhibited clear anomalous dispersions in the visible and near-infrared region (400-1200 nm), the modification is moderate for graphene on $\mathrm{SiO}_{2} / \mathrm{Si}$ substrate. Two graphene sheets have shown a pronounced absorption in the ultraviolet region with peak position related to the Van Hove singularity in the density of states. By increasing the temperature from $300 \mathrm{~K}$ to $500 \mathrm{~K}$, for monolayer graphene on $\mathrm{Si}$, the $\mathrm{n}$ value is gradually increased while $k$ decreased. However, the optical constants [n, $k]$ of monolayer graphene on $\mathrm{SiO}_{2} / \mathrm{Si}$ exhibited unpredictable wave variations. In the wavelength range of 400-1200 nm, an experiential formula of a like-Sellmeier equation is found well suited for describing the dispersions of graphene on $\mathrm{Si}$ and $\mathrm{SiO}_{2} / \mathrm{Si}$ substrates.
\end{abstract}

Keywords: graphene; spectroscopic ellipsometry; optical properties; temperature-dependent characteristics

\section{Introduction}

Since the seminal experimental realization of one atom thick graphene sheets [1] along with the measurements of quantum Hall effect [2], a great deal of interest has emerged in both the fundamental research and the development of device engineering concepts. Graphene has an extremely high carrier mobility $\sim 15,000 \mathrm{~cm}^{2} \mathrm{~V}^{-1} \mathrm{~S}^{-1}[3]$ and thermal conductivity $5000 \mathrm{~W} \mathrm{~m}^{-1} \mathrm{~K}^{-1}$ [4] with a very strong Young's modulus $\sim 1 \mathrm{TPa}$ [5]. The Dirac Fermions in graphene has caused both integer and fractional quantum Hall effect [6]. Unconventional superconductivity has also been realized in a 2-dimensional superlattice created by stacking two sheets of twisted graphene relative to each other by a small angle $[7,8]$. Along with the unique electronic features, graphene has displayed extraordinary optical responses. Graphene, being a one-atom-thick sheet of carbon exhibits significant absorption in the visible to infrared wavelength region $(2.3 \%)$ with reflectance less than $0.1 \%$ [9]. This means that a one-atom-thick graphene layer is extremely transparent having a high degree of flexibility with excellent optical properties.

As the variety of graphene for commercial applications is intensifying, so does the compulsion for scientists to exploit reliable characterization methods for studying basic properties and for engineers to design optoelectronic devices for achieving optimum performance. To assess the optical traits of graphene, several measurements have been performed using spinning-disc Picometrology (SDP), spectroscopic ellipsometry (SE), and transmission spectroscopy, etc. [10-27]. For graphene $\mathrm{SiO}_{2} / \mathrm{Si}$ wafer, the complex refractive index is measured earlier by SDP at $532 \mathrm{~nm}$ and $633 \mathrm{~nm}$ [10]. Optical constants of graphene 
have also been extracted by SE measurements [11-25]. However, the existing results of optical behavior for graphene are significantly different. The difference in outcomes is linked either to the methods used for preparing graphene samples with different numbers of layers and/or substrates.

This work aimed to understand the optical and temperature-dependent features of commercial graphene. A series of graphene samples were prepared by ACS Material, LLC using standard manufacturing procedures (product detail found on the website of https: / / www.acsmaterial.com/graphene-on-silicon-substrate.html accessed on 29 March 2021). Graphene was first prepared on copper foil by the chemical vapor deposition (CVD) method and then transferred onto $\mathrm{Si}$ and on $\mathrm{SiO}_{2} / \mathrm{Si}$ substrates. The graphene qualities are examined through Raman spectroscopy and atomic force microscopy (AFM). The temperature-dependent optical properties are systemically investigated by exploiting a variable angle spectroscopic ellipsometry (VASE) method. The refractive index (n) and extinction coefficient $(\mathrm{k})$ of the graphene sheets having different layers prepared on $\mathrm{Si}$ and $\mathrm{SiO}_{2} / \mathrm{Si}$ substrates are carefully analyzed, establishing temperature-dependence between $300 \mathrm{~K}$ and $500 \mathrm{~K}$. The anomalous optical dispersions of graphene prepared on $\mathrm{Si}$ and $\mathrm{SiO}_{2} / \mathrm{Si}$ in the visible to near-infrared wavelength region (i.e., $\lambda$ between 400 to $1200 \mathrm{~nm}$ ), are well described by a modified Sellmeier equation.

\section{Materials and Methods}

Four graphene samples were meticulously examined by using VASE and variable temperature methods. The samples considered here were: (a) monolayer and bilayer graphene on $\mathrm{Si}$ substrate, and (b) monolayer, bilayer graphene on $\mathrm{SiO}_{2} / \mathrm{Si}$ substrate $(\mathrm{a} \mathrm{Si}$ wafer covered with a $300 \mathrm{~nm} \mathrm{SiO}{ }_{2}$ layer). The dimensions of the graphene sheets were $2.54 \mathrm{~cm} \times 2.54 \mathrm{~cm}$. To examine the graphene qualities, room temperature Raman scattering spectra were measured using a micro-region Raman spectrometer with an excitation laser source of a wavelength of $532 \mathrm{~nm}$ and a spot size of $2 \mu \mathrm{m}$ (iHR550, HORIBA, Kyoto, Japan), and the surface morphology of the samples were examined by the atomic force microscope (Dimension Icon, BRUKER NANO Inc., Billerica, MA, USA). The SE measurements were performed by using a Müeller Matrix Ellipsometer (Wuhan Eoptics Technology Co. Ltd., Wuhan, China) equipped with a heating and cooling system (THMS600, Linkam, Surrey, UK). The optical constants were extracted by modeling and data fitting analysis. The SE has the advantages of being a non-destructive and highly accurate technique. In the VASE studies, we used deuterium and halogen sources and varied the incident angles from $50^{\circ}, 55^{\circ}, 60^{\circ}, 65^{\circ}$, and $70^{\circ}$, respectively. The beam size was about $4 \mathrm{~mm}$. To study the temperature-dependent characteristics of graphene, we recorded the angle of polarization psi $(\psi)$ and phase difference delta $(\Delta)$ of the reflective polarization lights between $300-500 \mathrm{~K}$ in the steps of $20 \mathrm{~K}$.

To extract the optical constants, we fitted and modeled the recorded data of psi $(\psi)$ and delta $(\Delta)$ by using Eometrics (Wuhan Eoptics Technology Co. Ltd., Wuhan, China). In our data analysis, a three-layer model was adopted, which properly included contributions from the substrate, oxide layer, and graphene, and the goodness of fitting was evaluated by the Mean Squared Error (MSE) method. Since the manufacturing procedures would induce a modification of bandgap properties of graphene [28-31], the dispersion properties of the graphene layers were described by 5 Tauc-Lorentz oscillators and 1 Drude oscillator. As for the oxide layer $\left(\mathrm{SiO}_{2}\right)$ and the substrate $(\mathrm{Si})$, their dispersions were described by the Sellmeier and parametric models which were provided by the materials database of Eometrics.

\section{Results and Discussion}

\subsection{Raman Scattering and AFM Measurements}

Raman spectroscopy was used to characterize the quality of the transferred graphene. Figure 1 shows the room temperature Raman scattering spectra recorded for four graphene samples, in which all samples displayed typical Raman peaks of graphene. All graphene 
samples included two intrinsic Raman peaks (G, 2D) and two disorder-induced peaks ( $\mathrm{D}, \mathrm{D}+\mathrm{D}^{\prime \prime}$ peaks for graphene on $\mathrm{Si}$, and $\mathrm{D}, \mathrm{D}^{\prime}+\mathrm{D}^{\prime \prime}$ peaks for graphene on $\mathrm{SiO}_{2}$ ) [32-34]. Among the defect-activated peaks, $\mathrm{D}^{\prime}+\mathrm{D}^{\prime \prime}$ and $\mathrm{D}+\mathrm{D}^{\prime \prime}$ corresponded to the combination mode of the $\mathrm{D}^{\prime}$ and $\mathrm{D}^{\prime \prime}$ modes as well as the $\mathrm{D}$ and $\mathrm{D}^{\prime \prime}$ modes [34]. Si had strong absorption in the visible wavelength, the intensity of Raman scattering light for the graphene on $\mathrm{Si}$ substrate was weaker than that of graphene on $\mathrm{SiO}_{2} / \mathrm{Si}$ substrate. The Raman scattering results indicated there existed a degree of defects in the four transferred graphene sheets. The intensity ratio between the $2 \mathrm{D}$ band and the $\mathrm{G}$ band can determine the number of graphene layers [35-37]. The $\mathrm{I}_{2 \mathrm{D}} / \mathrm{I}_{\mathrm{G}}$ values were higher than 2 , in the range between 1 and 2, and lower than 1, corresponding to the presence of monolayer graphene, bilayer graphene, and three or more layers, respectively [35]. As for our four graphene samples, the $\mathrm{I}_{2 \mathrm{D}} / \mathrm{I}_{\mathrm{G}}$ values of two monolayer graphene were respectively 2.1 (on Si substrate) and 3.4 (on $\mathrm{SiO}_{2} / \mathrm{Si}$ substrate) while those of two bilayer graphene were 1.5 (on $\mathrm{Si}$ substrate) and $1.7\left(\mathrm{SiO}_{2} / \mathrm{Si}\right.$ substrate) .
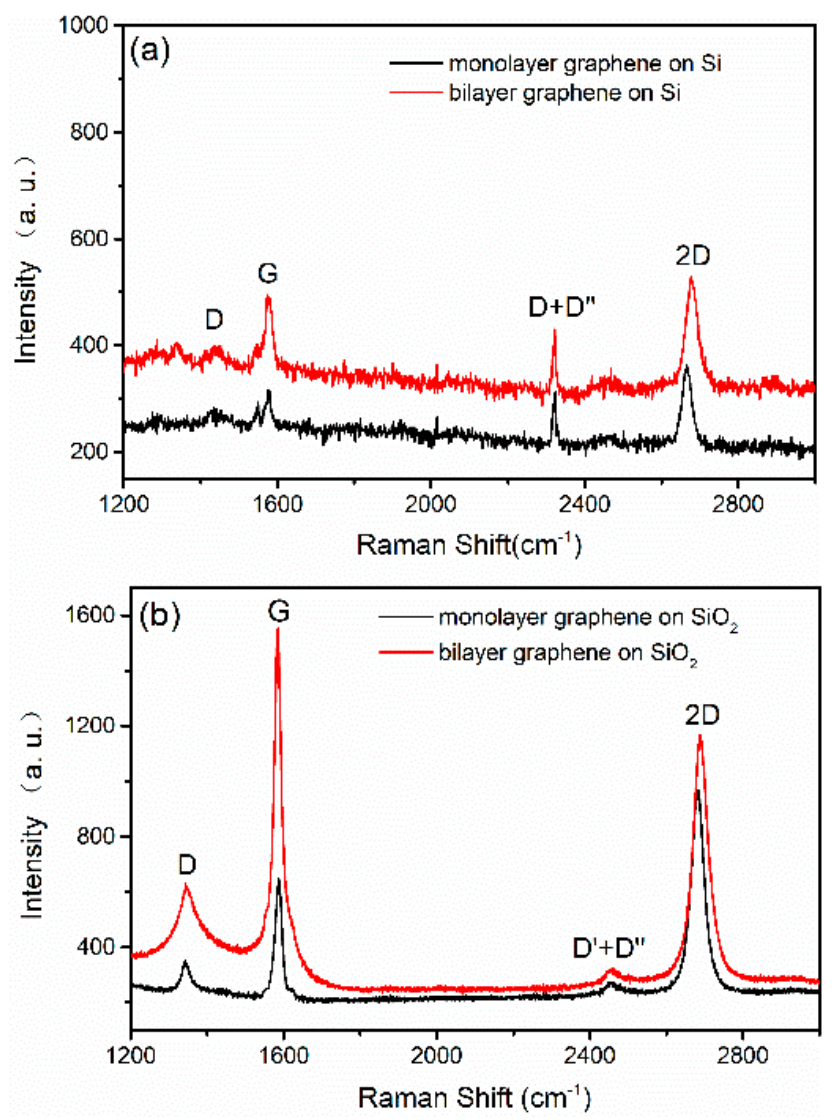

Figure 1. Raman scattering spectra of graphene samples. (a) graphene on Si substrate; (b) graphene on $\mathrm{SiO}_{2} / \mathrm{Si}$ substrate.

Figure 2 illustrates the AFM images of graphene samples displaying smooth surfaces with a few surface contaminants. In $2 \mu \mathrm{m} \times 2 \mu \mathrm{m}$ AFM images, the Root Mean Square (RMS) roughness was around 1.5-4.5 nm and the average roughness was $0.6-0.9 \mathrm{~nm}$ respectively. The samples had enough smooth surfaces for SE measurements and analysis. 

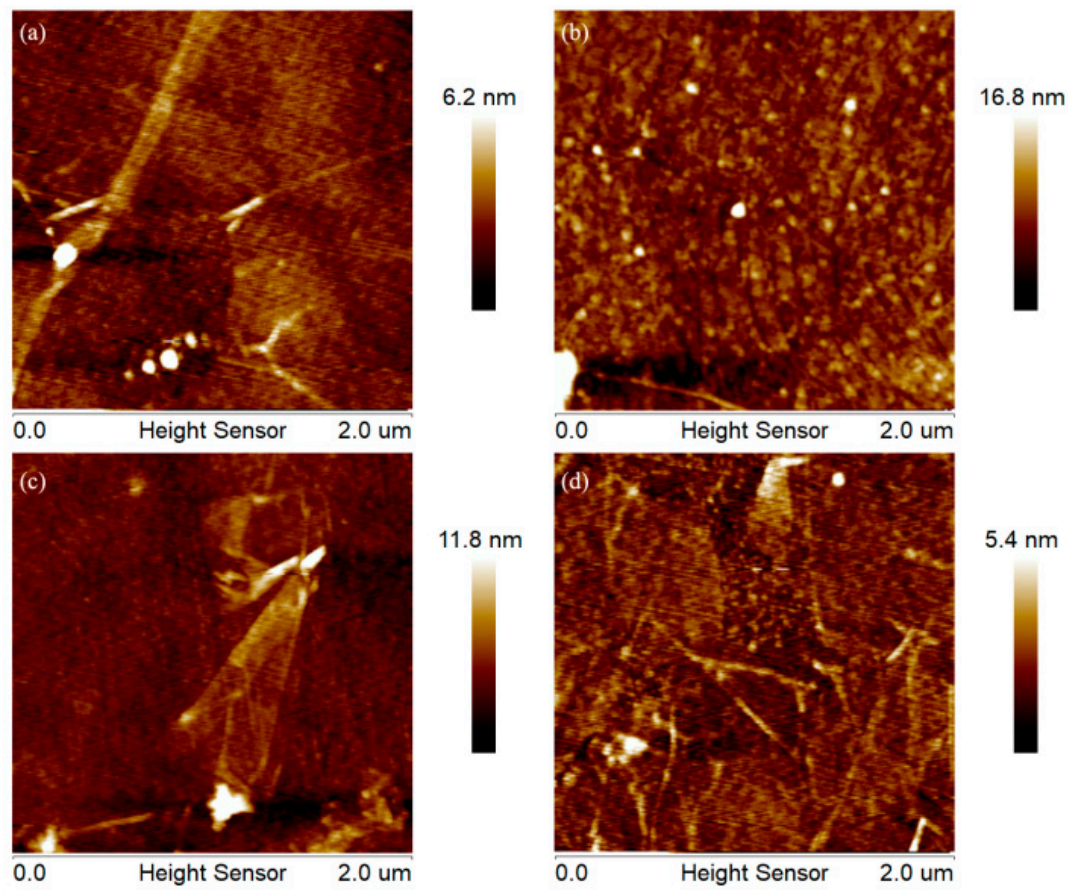

Figure 2. Atomic force microscopy (AFM) images of graphene samples. (a) monolayer graphene on Si substrate; (b) bilayer graphene on Si substrate; (c) monolayer graphene on $\mathrm{SiO}_{2}$ substrate; (d) bilayer graphene on $\mathrm{SiO}_{2}$ substrate.

\subsection{Spectroscopic Ellipsometric Measurements}

The optical characteristics of graphene samples were investigated by variable angle spectroscopic ellipsometry. In Figure 3a-d we have displayed the measured psi $(\psi)$ and $\operatorname{delta}(\Delta)$ at $300 \mathrm{~K}$ for monolayer graphene samples on $\mathrm{Si}$ and $\mathrm{SiO}_{2} / \mathrm{Si}$ substrates, respectively by varying incident angles from $50^{\circ}, 55^{\circ}, 60^{\circ}, 65^{\circ}$, and $70^{\circ}$. The experimental data (black solid lines) and the fitted curves (red dotted lines) compared reasonably well. In Table 1 , for four samples the thicknesses of graphene and oxide layers and the MSE values are presented. The low MSE values ( $<15$ in Table 1) indicated good fits. The thicknesses of monolayer graphene on $\mathrm{Si}$ and on $\mathrm{SiO}_{2} / \mathrm{Si}$ were $0.38 \mathrm{~nm}$ and $0.34 \mathrm{~nm}$, respectively, which was in accordance with those previously reported [13,16,21,25]. In Table 2, the fitting parameters of Tauc-Lorentz and Drude oscillators for monolayer graphene on $\mathrm{Si}$ and $\mathrm{SiO}_{2} / \mathrm{Si}$ substrates are presented, where $\mathrm{Amp}_{\mathrm{n}}, \mathrm{Br}_{\mathrm{n}}, \mathrm{Eo}_{\mathrm{n}}$, and $\mathrm{Eg}_{\mathrm{n}}$ correspond to amplitude, broadening, center energy, and bandgap energy of oscillator $n$ ( $n$ is an integer), and Scat. Time is scattering time, respectively. The bandgap energy of Tauc-Lorentz oscillators as shown in Table 2 well agreed with the reports in References [28-31], indicating the dispersion models for graphene layers we have chosen were reasonable.

The extracted optical constants ( $\mathrm{n}$ and $\mathrm{k}$ ) in the wavelength range of $218-1200 \mathrm{~nm}$ are shown in Figure 3e,f. It is to be noted that graphene sheets on $\mathrm{Si}$ and on $\mathrm{SiO}_{2} / \mathrm{Si}$ exhibited markedly different optical properties. In the range of $\lambda$ between $400-1200 \mathrm{~nm}$, the monolayer graphene on $\mathrm{Si}$ exhibited anomalous dispersions with a larger extinction coefficient than those on $\mathrm{SiO}_{2} / \mathrm{Si}$. In the ultraviolet wavelength range $\lambda$ between $220-400 \mathrm{~nm}$, the $\mathrm{n}$ of monolayer graphene on $\mathrm{Si}$ displayed a sharp peak while on $\mathrm{SiO}_{2} / \mathrm{Si}$ it revealed a moderate feature. Likewise, the $\mathrm{k}$ of monolayer graphene on $\mathrm{Si}$ exhibited a pronounced peak at $\sim 4.64 \mathrm{eV}$ while a weak peak was noticed at $\sim 4.78 \mathrm{eV}$ for graphene on $\mathrm{SiO}_{2} / \mathrm{Si}$. The peak position of $k$, which is considered as a van Hove singularity of graphene density of state [11], showed an energy difference of $0.14 \mathrm{eV}$ for two samples. Obviously, the interaction of graphene with substrate had significantly affected the optical properties of graphene. 

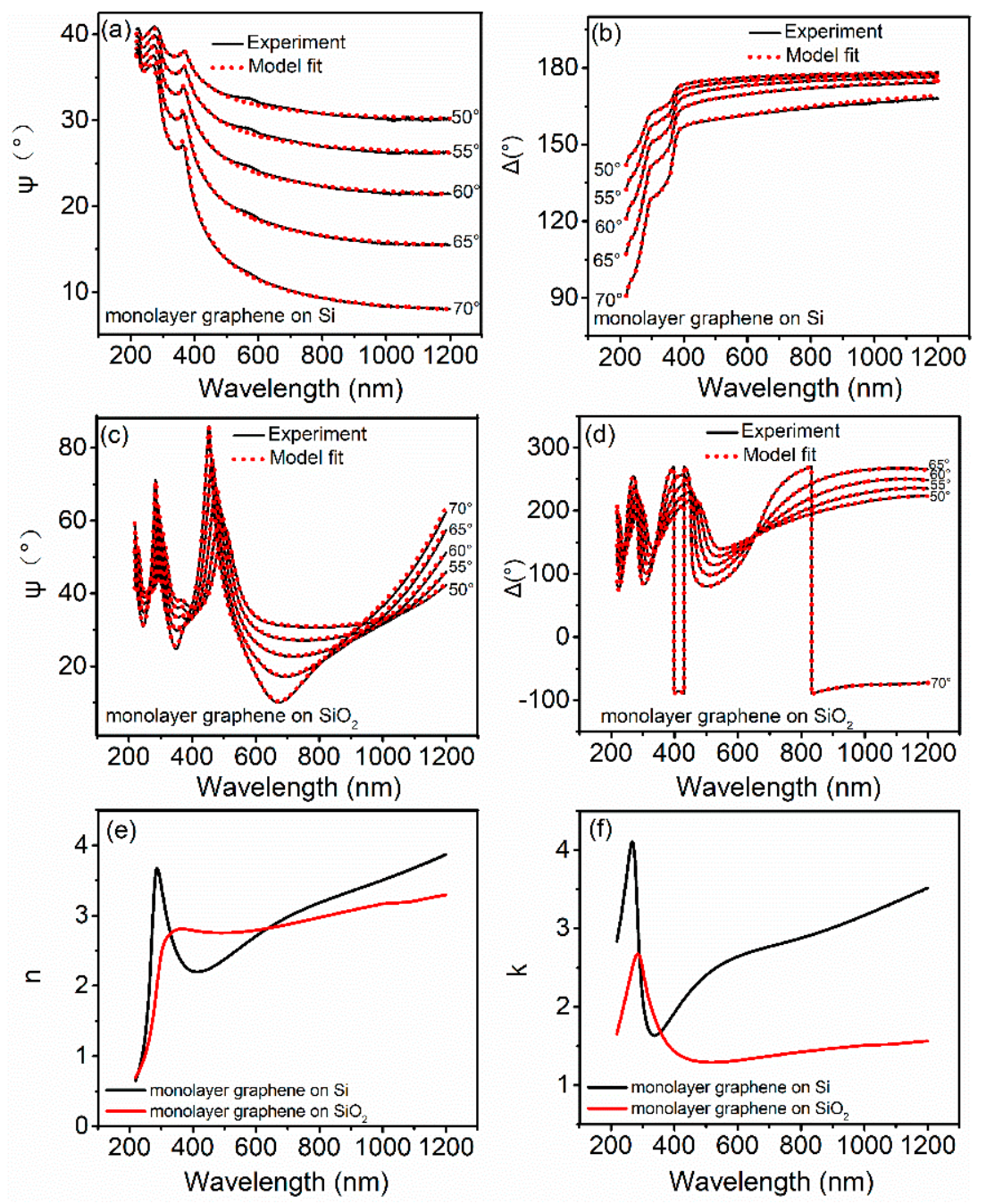

Figure 3. Variable angle spectroscopic ellipsometry of graphene on $\mathrm{Si}$ and on $\mathrm{SiO}_{2} / \mathrm{Si}$ substrates at room temperature. the measured (black line) and fitting (red dot) $\operatorname{psi}(\psi)$ and $\operatorname{delta}(\Delta)$ spectra for the monolayer graphene on $\mathrm{Si}$ substrate $(\mathbf{a}, \mathbf{b})$ and on $\mathrm{SiO}_{2} / \mathrm{Si}$ substrate $(\mathbf{c}, \mathbf{d}),(\mathbf{e}, \mathbf{f})$ represent the extracted refractive indices $(n)$ and the extinction coefficients $(k)$ by SE fitting.

Table 1. Thicknesses and mean squared error (MSE) values of graphene samples.

\begin{tabular}{|c|c|c|c|c|c|}
\hline \multicolumn{2}{|c|}{ Samples } & \multirow{2}{*}{$\begin{array}{c}1 \text { Layer on Si } \\
0.380 \pm 0.002\end{array}$} & \multirow{2}{*}{$\begin{array}{l}2 \text { Layers on Si } \\
0.730 \pm 0.005\end{array}$} & \multirow{2}{*}{$\begin{array}{c}\begin{array}{c}1 \text { Layer on } \\
\mathrm{SiO}_{2} / \mathrm{Si}\end{array} \\
0.340 \pm 0.001\end{array}$} & \multirow{2}{*}{$\begin{array}{c}\begin{array}{c}2 \text { Layers on } \\
\mathbf{S i O}_{\mathbf{2}} / \mathbf{S i}\end{array} \\
0.880 \pm 0.001\end{array}$} \\
\hline Thickness & Graphene & & & & \\
\hline (nm) & Oxide Layer & $4.560 \pm 0.004$ & $4.700 \pm 0.008$ & $297.980 \pm 0.011$ & $293.370 \pm 0.011$ \\
\hline \multicolumn{2}{|c|}{ MSE } & 4.252 & 4.868 & 11.564 & 13.498 \\
\hline
\end{tabular}

Moreover, we compared the optical constants of monolayer and bilayer graphene. In Figure 4 the optical constants extracted by SE measurements are displayed for four graphene samples along with the fitted results. We noticed that for graphene samples on $\mathrm{Si}$ substrate, the $\mathrm{n}$ decreased while $\mathrm{k}$ increased with the increase in the number of layers. Moreover, the peak positions of $\mathrm{k}$ were found redshifted. This was possibly due to the increase of the number of layers-the layer-to-layer interaction decreased the energy of $\pi$-to- $\pi^{*}$ exciton transition near the M point of the Brillouin zone $[38,39]$. Unlike graphene on $\mathrm{Si}$, the bilayer graphene on $\mathrm{SiO}_{2} / \mathrm{Si}$ displayed a greater $\mathrm{n}$ than that of monolayer graphene as wavelengths were longer than $600 \mathrm{~nm}$. Moreover, it exhibited significant dispersion features compared to the monolayer graphene on $\mathrm{SiO}_{2} / \mathrm{Si}$. It has been suggested earlier that 
the substrates modulate the dispersion of graphene sheets and the enhanced layer-to-layer interaction of graphene degrades the excitonic effects [38-40].

Table 2. The fitting parameters of Tauc-Lorentz and Drude oscillators for monolayer graphene on $\mathrm{Si}$ and $\mathrm{SiO}_{2} / \mathrm{Si}$ substrates $(300 \mathrm{~K})$.

\begin{tabular}{|c|c|c|c|c|c|}
\hline Graphene Samples & Tauc-Lorentz & $\mathrm{Amp}_{1}=108.5431$ & $\mathrm{Br}_{1}=1.024$ & $\mathrm{Eo}_{1}=0.433 \mathrm{eV}$ & $\mathrm{Eg}_{1}=0.138 \mathrm{eV}$ \\
\hline \multirow{5}{*}{ Monolayer on Si } & Tauc-Lorentz & $\mathrm{Amp}_{2}=26.2332$ & $\mathrm{Br}_{2}=2.677$ & $\mathrm{Eo}_{2}=2.085 \mathrm{eV}$ & $\mathrm{Eg}_{2}=0.233 \mathrm{eV}$ \\
\hline & Tauc-Lorentz & $\mathrm{Amp}_{3}=11.5482$ & $\mathrm{Br}_{3}=7.543$ & $\mathrm{Eo}_{3}=2.944 \mathrm{eV}$ & $\mathrm{Eg}_{3}=0 \mathrm{eV}$ \\
\hline & Tauc-Lorentz & $\mathrm{Amp}_{4}=7.2054$ & $\mathrm{Br}_{4}=1.307$ & $\mathrm{Eo}_{4}=4.492 \mathrm{eV}$ & $\mathrm{Eg}_{4}=0.191 \mathrm{eV}$ \\
\hline & Tauc-Lorentz & $\mathrm{Amp}_{5}=14.3884$ & $\mathrm{Br}_{5}=0.56$ & $\mathrm{EO}_{5}=4.477 \mathrm{eV}$ & $\mathrm{Eg}_{5}=0.87 \mathrm{eV}$ \\
\hline & Drude & $\begin{array}{l}\text { Rsisitivity = } \\
0.0008 \Omega \mathrm{cm}\end{array}$ & $\begin{array}{c}\text { Scat. Time }= \\
12.576 \mathrm{fs}\end{array}$ & 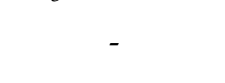 & 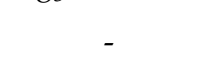 \\
\hline \multirow{6}{*}{ Monolayer on $\mathrm{SiO}_{2} / \mathrm{Si}$} & Tauc-Lorentz & $\mathrm{Amp}_{1}=41.068$ & $\mathrm{Br}_{1}=2.783$ & $\mathrm{Eo}_{1}=0.329 \mathrm{eV}$ & $\mathrm{Eg}_{1}=0.174 \mathrm{eV}$ \\
\hline & Tauc-Lorentz & $\mathrm{Amp}_{2}=24.0227$ & $\mathrm{Br}_{1}=2.783$ & $\mathrm{Eo}_{2}=1.799 \mathrm{eV}$ & $\mathrm{Eg}_{2}=0.188 \mathrm{eV}$ \\
\hline & Tauc-Lorentz & $\mathrm{Amp}_{3}=14.095$ & $\mathrm{Br}_{3}=3.618$ & $\mathrm{Eo}_{3}=3.739 \mathrm{eV}$ & $\mathrm{Eg}_{3}=0.476 \mathrm{eV}$ \\
\hline & Tauc-Lorentz & $\mathrm{Amp}_{4}=9.9583$ & $\mathrm{Br}_{4}=1.641$ & $\mathrm{Eo}_{4}=4.172 \mathrm{eV}$ & $\mathrm{Eg}_{4}=0.554 \mathrm{eV}$ \\
\hline & Tauc-Lorentz & $\mathrm{Amp}_{5}=15.58$ & $\mathrm{Br}_{5}=0.904$ & $\mathrm{Eo}_{5}=4.594 \mathrm{eV}$ & $\mathrm{Eg}_{4}=2.077 \mathrm{eV}$ \\
\hline & Drude & $\begin{array}{l}\text { Rsisitivity = } \\
1000 \Omega \mathrm{cm}\end{array}$ & $\begin{array}{l}\text { Scat. Time }= \\
1000 \mathrm{fs}\end{array}$ & 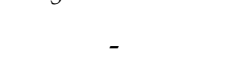 & 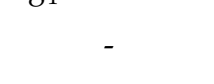 \\
\hline
\end{tabular}
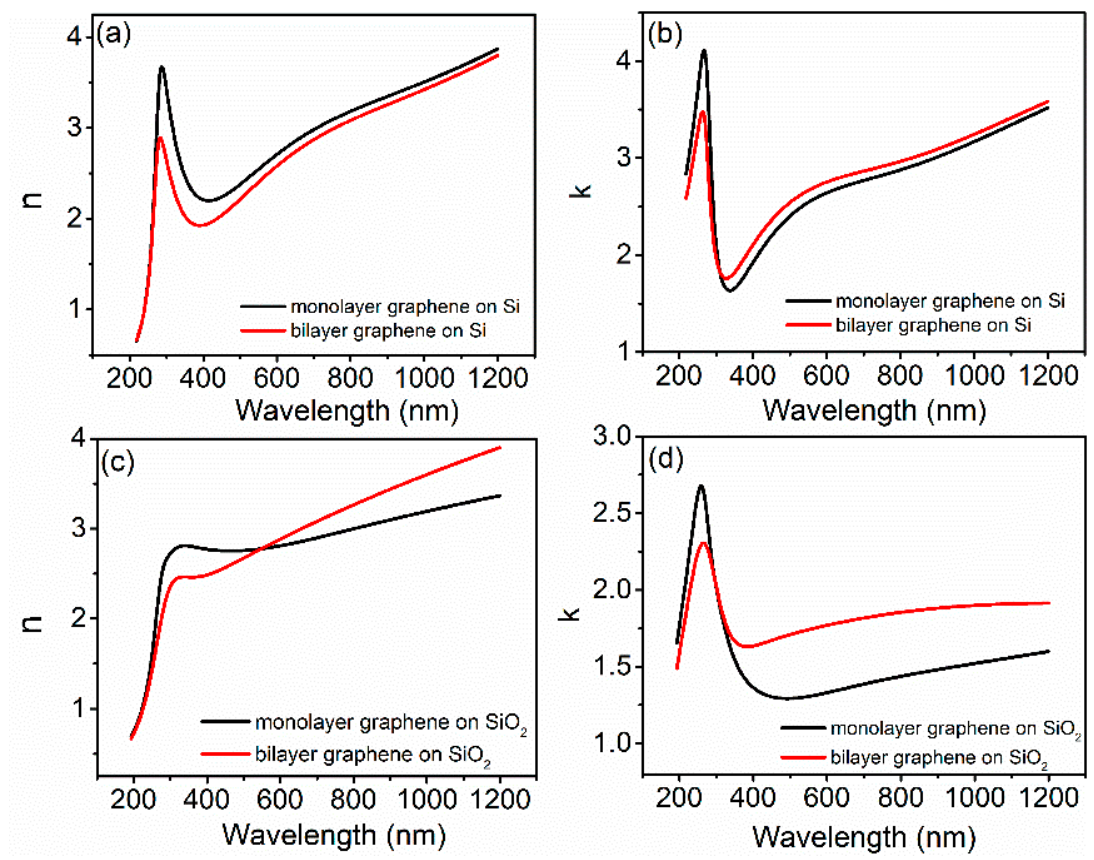

Figure 4. Layer-dependent optical constants of graphene on $\mathrm{Si}(\mathbf{a}, \mathbf{b})$ and on $\mathrm{SiO}_{2} / \mathrm{Si}$ substrate (c,d).

In Figure 5 we have displayed the results of temperature-dependent optical constants for two monolayer graphene on $\mathrm{Si}$ and $\mathrm{SiO}_{2} / \mathrm{Si}$ substrates from $300 \mathrm{~K}$ to $500 \mathrm{~K}$ with a step of $20 \mathrm{~K}$. The optical constants of monolayer graphene on Si varied consistently with temperature. In the region of $\lambda$ between 400 to $1200 \mathrm{~nm}$, we noticed the $\mathrm{n}$ increased while $\mathrm{k}$ decreased with the increase of temperature because the coupling between light and electrons was intensified in graphene. However, the optical constants [n, $\mathrm{k}$ ] of monolayer graphene on $\mathrm{SiO}_{2} / \mathrm{Si}$ exhibited unpredictable variations, i.e., the refractive index $\mathrm{n}$ and the extinction coefficient $\mathrm{k}$ displayed fluctuations with the increase of temperature. 

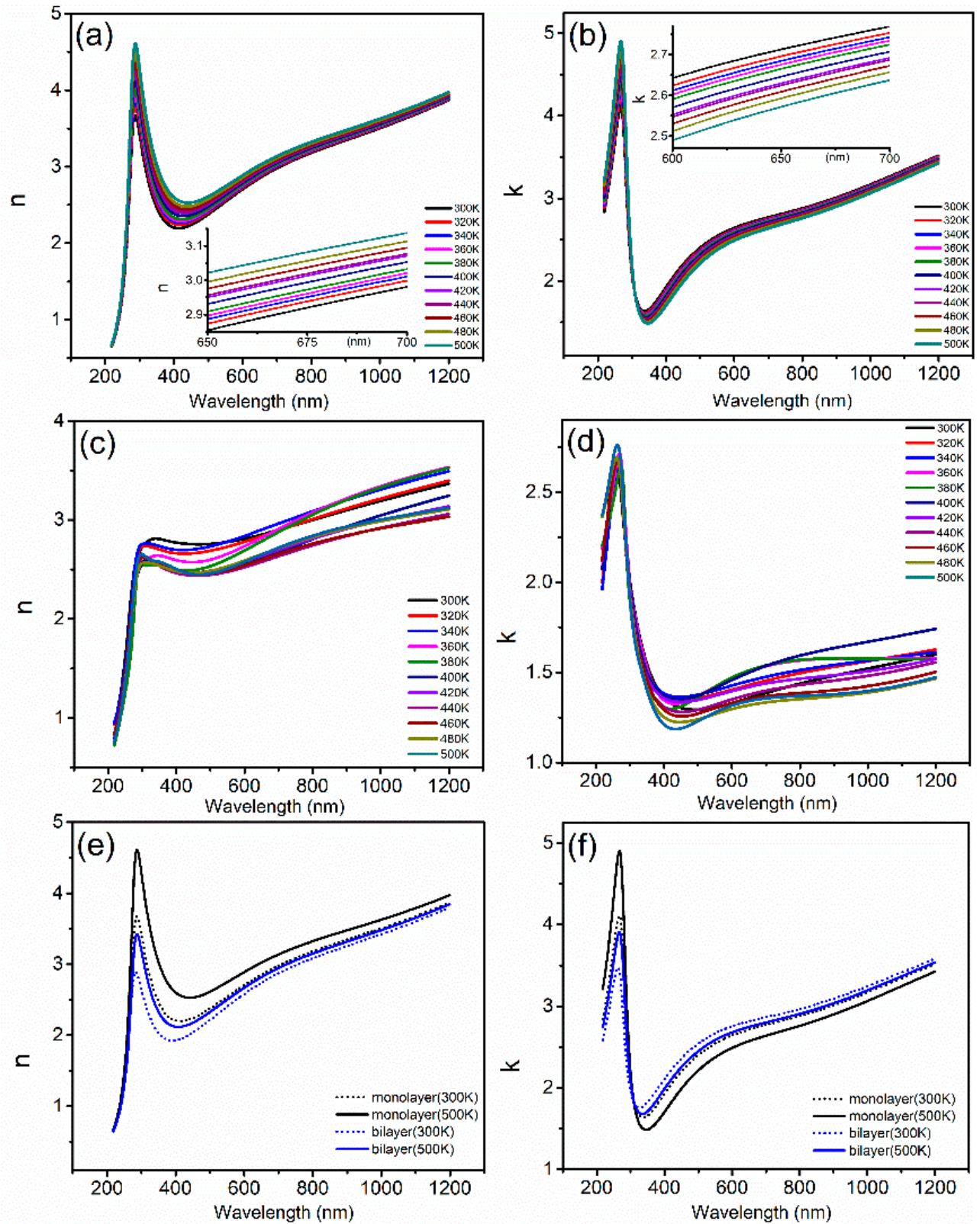

Figure 5. Temperature-dependent optical constants of graphene on $\mathrm{Si}$ substrate $(\mathbf{a}, \mathbf{b})$ and on $\mathrm{SiO}_{2} / \mathrm{Si}$ substrate (c,d) from $300 \mathrm{~K}$ to $500 \mathrm{~K}$ with a step of $20 \mathrm{~K}$. (e,f) optical constants of four graphene samples on $\mathrm{Si}$ at $300 \mathrm{~K}$ and at $500 \mathrm{~K}$.

Figure 5e,f illustrates respectively the difference of the extracted optical constants by VASE measurements for four samples of graphene sheets prepared on Si substrate at $300 \mathrm{~K}$ and at $500 \mathrm{~K}$. It was revealed that the difference of optical constants between $300 \mathrm{~K}$ and $500 \mathrm{~K}$ for the monolayer graphene on $\mathrm{Si}$ were bigger than those of bilayer graphene, suggesting more temperature sensitivity of the monolayer graphene. It could be caused by the fact that monolayer graphene has more defects, stronger graphene-substrate interactions, and lower thermal stability. The temperature effect was relatively smaller and the thermal stability was enhanced with the increasing number of layers.

Graphene is usually applied in photoelectric devices. The optical constant $n(\lambda)$ reflects the dispersion properties of graphene. It is essential to understand the dependence of dispersion properties of graphene on wavelength and temperature in the transparent region. To further explore the specific dispersion relationship of graphene on $\mathrm{Si}$ and on $\mathrm{SiO}_{2} / \mathrm{Si}$ substrates, we fitted the $\mathrm{n}$ by using a like-Sellmeier equation based on the extracted data 
in the wavelength range of $\lambda$ between $400-1200 \mathrm{~nm}$ at room temperature. The traditional Sellmeier equation describing the dispersion is given by [41]:

$$
n(\lambda)=\left[1+\sum_{j=1} \frac{A_{j} \lambda^{2}}{\lambda^{2}-B_{j}}\right]^{1 / 2}
$$

where $\lambda$ is the wavelength, $A_{j}$ and $B_{j}$ are the fitting parameters, and $j$ is an integer. The fitting results for monolayer and bilayer graphene are displayed in Figure 6. The dispersion curves of graphene on Si were fitted well by a like-Sellmeier equation with $j=1$ and for graphene on $\mathrm{SiO}_{2} / \mathrm{Si}$ with $j=2$. The fitting parameters are recorded in Table 3 and the fitting parameter $B_{1}$ was negative which mainly reflected an anomalous dispersion of graphene. It is worth noting that graphene on $\mathrm{SiO}_{2} / \mathrm{Si}$ possessed more complex dispersion features. It was possibly caused by an enhancing layer-to-layer interaction which complicated the dispersion relationship.

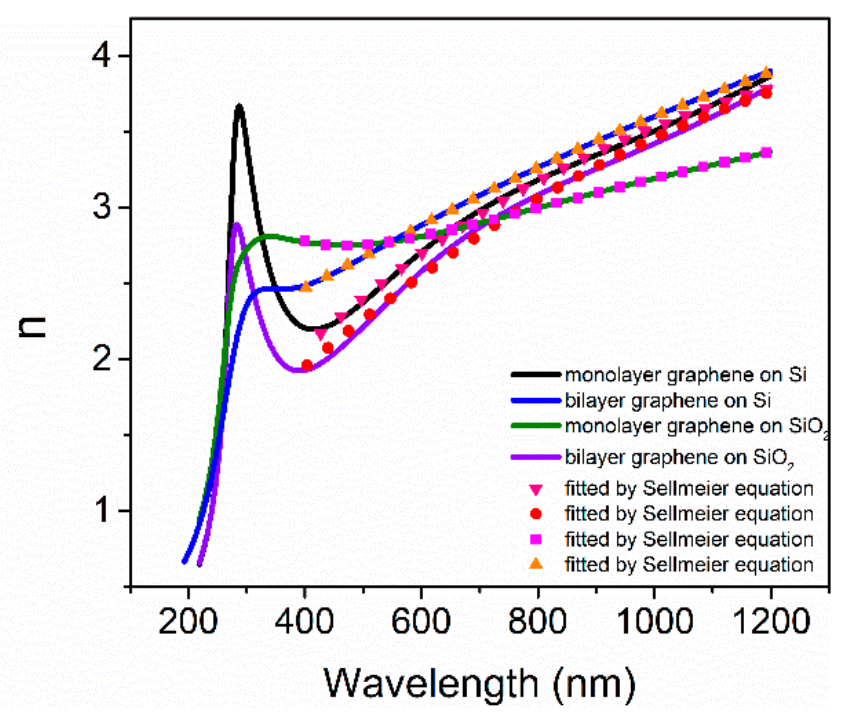

Figure 6. The refractive indices of graphene on $\mathrm{Si}$ and on $\mathrm{SiO}_{2} / \mathrm{Si}$ substrates fitted by a like-Sellmeier Equation (1) in the wavelength range of 400-1200 nm.

Table 3. Fitting parameters of graphene on $\mathrm{Si}$ and on $\mathrm{SiO}_{2} / \mathrm{Si}$ substrates by using a like-Sellmeier Equation (1).

\begin{tabular}{cccccc}
\hline Graphene Samples & $\boldsymbol{A}_{\mathbf{1}}$ & $\boldsymbol{B}_{\mathbf{1}}\left(\times \mathbf{1 0}^{\mathbf{5}} \mathbf{n m}^{\mathbf{2}}\right)$ & $\boldsymbol{A}_{\mathbf{2}}$ & $\boldsymbol{B}_{\mathbf{2}}\left(\times \mathbf{1 0}^{\mathbf{5}} \mathbf{n m}^{\mathbf{2}}\right)$ & - \\
\hline monolayer on $\mathrm{Si}$ & $21.40 \pm 0.05$ & $-8.674 \pm 0.034$ & - & - & 0.99747 \\
bilayer on $\mathrm{Si}$ & $24.486 \pm 0.124$ & $-12.360 \pm 0.095$ & - & 0.99418 \\
monolayer on $\mathrm{SiO}_{2}$ & $13.682 \pm 0.025$ & $-17.006 \pm 0.078$ & $3.935 \pm 0.006$ & $0.466 \pm 0.001$ & 0.99987 \\
bilayer on $\mathrm{SiO}_{2}$ & $25.107 \pm 0.074$ & $-20.045 \pm 0.162$ & $3.713 \pm 0.025$ & $-0.238 \pm 0.008$ & 0.99992 \\
\hline
\end{tabular}

Furthermore, for graphene on Si substrate, the parameters $A_{1}$ and $B_{1}$ as a function of temperature $(T)$ were well represented by a polynomial which is given by.

$$
\begin{aligned}
& A_{1}(T)=a_{0}+a_{1} T+a_{2} T^{2} \\
& B_{1}(T)=b_{0}+b_{1} T+b_{2} T^{2}
\end{aligned}
$$

where $a_{0}, a_{1}, a_{2}, b_{0}, b_{1}$, and $b_{2}$ are constants. By substituting the testing temperature and values of $A_{1}$ and $B_{1}$ into Equation (2) the fitted results are shown in Figure 7. The red solid lines are the fitted curves using Equation (2), with parameter values of $a_{0}, a_{1}, a_{2}, b_{0}, b_{1}$, and $b_{2}$ tabulated in Table 4. Combining the fitting results of expressions (1) and (2), the complete dispersion and temperature-dependent properties of graphene were revealed. 


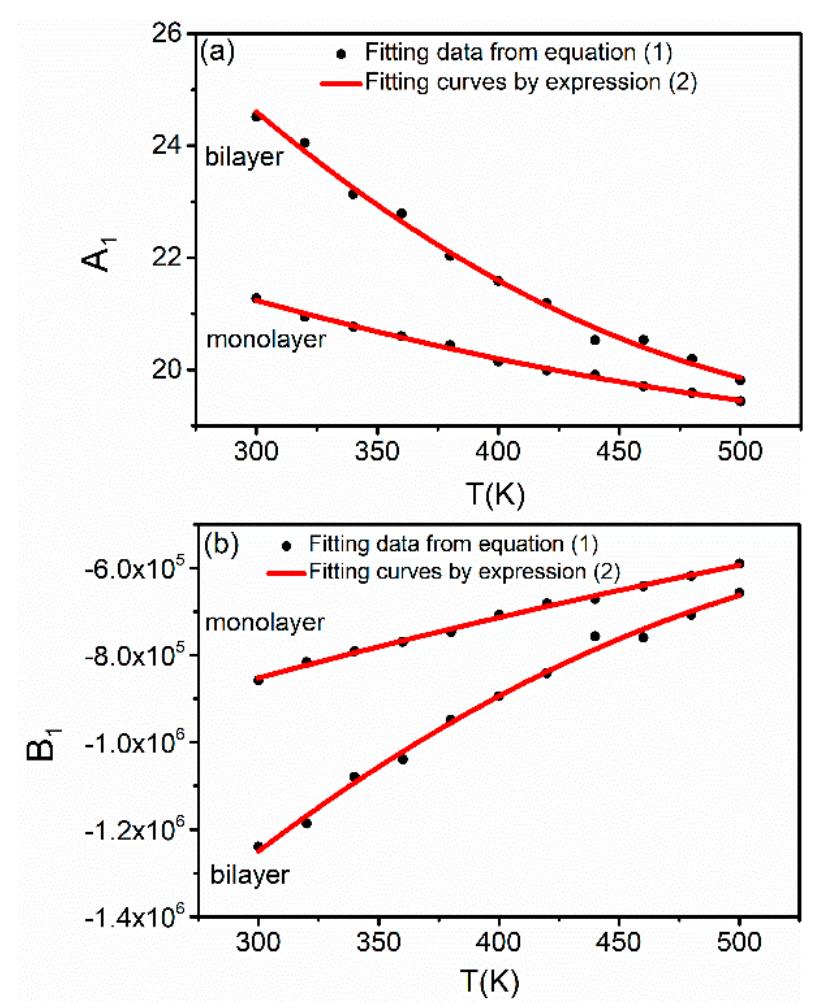

Figure 7. The parameters $A_{1}$ and $B_{1}$ as a function of temperature from $300 \mathrm{~K}$ to $500 \mathrm{~K}$ for the graphene on Si substrate.

Table 4. The fitting parameters using Equation (2) for graphene on Si.

\begin{tabular}{ccccccc}
\hline $\begin{array}{c}\text { Graphene } \\
\text { Samples }\end{array}$ & $\boldsymbol{a}_{\mathbf{0}}$ & $\boldsymbol{a}_{\mathbf{1}}$ & $\boldsymbol{a}_{\mathbf{2}}\left(\times \mathbf{1 0}^{-\mathbf{5}} \mathbf{K}^{-\mathbf{2}}\right)$ & $\boldsymbol{b}_{\mathbf{0}}(\times \mathbf{1 0} \mathbf{\mathbf { n m }})$ & $\boldsymbol{b}_{\mathbf{1}}\left(\mathbf{1 \mathbf { 1 } ^ { \mathbf { 3 } }} \mathbf{n m}^{\mathbf{2}} \mathbf{K}^{-\mathbf{1}}\right)$ & $\boldsymbol{b}_{\mathbf{2}}\left(\mathbf{n m}^{\mathbf{2}} \mathbf{K}-\mathbf{2}\right)$ \\
\hline $\begin{array}{c}\text { monolayer on Si } \\
\text { bilayer on Si }\end{array}$ & $26.16 \pm 0.58$ & $-0.020 \pm 0.002$ & $1.495 \pm 0.368$ & $-1.379 \pm 0.085$ & $2.038 \pm 0.430$ & $-0.932 \pm 0.530$ \\
\hline
\end{tabular}

\section{Conclusions}

In summary, the results of the comprehensive study for the optical properties of graphene revealed interesting characteristics which are not only substrate-, layer- but also temperature-dependent. The graphene samples on Si substrate exhibited significant dispersion features and higher exciton transition energy than those on $\mathrm{SiO}_{2} / \mathrm{Si}$ substrate. With the increase of temperatures from $300 \mathrm{~K}$ to $500 \mathrm{~K}$, the optical constants of monolayer graphene on $\mathrm{Si}$ varies regularly while the monolayer graphene on $\mathrm{SiO}_{2} / \mathrm{Si}$ has fluctuations. An experiential formula of a like-Sellmeier expression is demonstrated well exemplifying the wavelength dependence of refractive indices of monolayer and bilayer graphene samples. In addition, for monolayer graphene on $\mathrm{Si}$, the temperature-dependent dispersion properties are well described by combining the like-Sellmeier equation and a quadratic expression.

Author Contributions: Conceptualization, L.W. (Lingyu Wan) and S.W.; Data curation, S.W. and L.W. (Liangmin Wei); Formal analysis, L.W. (Lingyu Wan) and S.W.; Funding acquisition, L.W. (Lingyu Wan); Investigation, L.W. (Lingyu Wan), S.W. and Z.F.; Project administration, L.W. (Lingyu Wan); Resources, L.W. (Lingyu Wan), K.H. and Z.F.; Supervision, L.W. (Lingyu Wan); Writing-original draft, L.W. (Lingyu Wan) and S.W.; Writing-review \& editing, L.W. (Lingyu Wan), D.N.T. and Z.F. All authors have read and agreed to the published version of the manuscript.

Funding: This research was funded by the Guangxi Natural Science Foundation, China (2018GXNSFAA138127). 
Conflicts of Interest: The authors declare no conflict of interest.

\section{References}

1. Novoselov, K.S.; Geim, A.K.; Morozov, S.V.; Jiang, D.; Zhang, Y.; Dubonos, S.V.; Grigorieva, I.V.; Firsov, A.A. Electric Field Effect in Atomically Thin Carbon Films. Science 2004, 306, 666-669. [CrossRef]

2. Novoselov, K.S.; Geim, A.K.; Morozov, S.V.; Jiang, D.; Katsnelson, M.I.; Grigorieva, I.V.; Dubonos, S.V.; Firsov, A.A. Twodimensional gas of massless Dirac fermions in graphene. Nature 2005, 438, 197-200. [CrossRef]

3. Geim, A.K.; Novoselov, K.S. The rise of graphene. Nat. Mater. 2007, 6, 183-191. [CrossRef] [PubMed]

4. Balandin, A.A.; Ghosh, S.; Bao, W.Z.; Calizo, I.; Teweldebrhan, D.; Miao, F.; Lau, C.N. Superior Thermal Conductivity of Single-Layer Graphene. Nano Lett. 2008, 8, 902-907. [CrossRef]

5. Lee, C.; Wei, X.; Kysar, J.W.; Hone, J. Measurement of the Elastic Properties and Intrinsic Strength of Monolayer Graphene. Science 2008, 321, 385-388. [CrossRef]

6. Novoselov, K.S.; Jiang, Z.; Zhang, Y.; Morozov, S.V.; Stormer, H.L.; Zeitler, U. Room-Temperature Quantum Hall Effect in Graphene. Science 2007, 315, 1379. [CrossRef]

7. Wu, F.C.; Hwang, E.; Das Sarma, S. Phonon-induced giant linear-in-T resistivity in magic angle twisted bilayer graphene: Ordinary strangeness and exotic superconductivity. Phys. Rev. B 2019, 99, 165112. [CrossRef]

8. Lu, X.B.; Stepanov, P.; Yang, W.; Xie, M.; Aamir, M.A.; Das, I.; Urgell, C.; Watanabe, K.; Taniguchi, T.; Zhang, G.Y.; et al Superconductors, orbital magnets and correlated states in magic-angle bilayer graphene. Nature 2019, 574, 653-657. [CrossRef] [PubMed]

9. Nair, R.R.; Blake, P.; Grigorenko, A.N.; Novoselov, K.S.; Booth, T.J.; Stauber, T.; Peres, N.M.R.; Geim, A.K. Fine Structure Constant Defines Visual Transparency of Graphene. Science 2008, 320, 1308. [CrossRef]

10. Wang, X.F.; Chen, Y.P.; Nolte, D.D. Strong anomalous optical dispersion of graphene: Complex refractive index measured by Picometrology. Opt. Express 2008, 16, 22105-22112. [CrossRef]

11. Kravets, V.G.; Grigorenko, A.N.; Nair, R.R.; Blake, P.; Anissimova, S.; Novoselov, K.S.; Geim, A.K. Spectroscopic ellipsometry of graphene and an exciton-shifted van Hove peak in absorption. Phys. Rev. B 2010, 81, 115413. [CrossRef]

12. Wurstbauer, U.; Roling, C.; Wurstbauer, U.; Wegscheider, W.; Vaupel, M.; Thiesen, P.H.; Weiss, D. Imaging ellipsometry of graphene. Appl. Phys. Lett. 2010, 97, 231901. [CrossRef]

13. Weber, J.W.; Calado, V.E.; van de Sanden, M.C.M. Optical constants of graphene measured by spectroscopic ellipsometry. Appl. Phys. Lett. 2010, 97, 091904. [CrossRef]

14. Nelson, F.J.; Kamineni, V.K.; Zhang, T.; Comfort, E.S.; Lee, J.U.; Diebold, A.C. Optical properties of large-area polycrystalline chemical vapor deposited graphene by spectroscopic ellipsometry. Appl. Phys. Lett. 2010, 97, 253110. [CrossRef]

15. Isić, G.; Jakovljević, M.; Filipović, M.; Jovanović, D.; Vasić, B.; Lazović, S.; Puač, N.; Petrović, Z.L.; Kostić, R.; Gajić, R.; et al. Spectroscopic ellipsometry of few-layer graphene. J. Nanophotonics 2011, 5, 051809. [CrossRef]

16. Losurdo, M.; Giangregorio, M.M.; Capezzuto, P.; Bruno, G. Ellipsometry as a Real-Time Optical Tool for Monitoring and Understanding Graphene Growth on Metals. J. Phys. Chem. C 2011, 115, 21804-21812. [CrossRef]

17. Kostruba, A.M. Influence of the graphene substrate on morphology of the gold thin film. Spectroscopic ellipsometry study. Appl. Surf. Sci. 2013, 283, 603-611. [CrossRef]

18. Matković, A.; Ralević, U.; Chhikara, M.; Jakovljević, M.M.; Jovanović, D.; Bratina, G.; Gajić, R. Influence of transfer residue on the optical properties of chemical vapor deposited graphene investigated through spectroscopic ellipsometry. J. Appl. Phys. 2013, 114, 93505. [CrossRef]

19. Shen, C.C.; Tseng, C.C.; Lin, C.T.; Li, L.J.; Liu, H.L. Optical properties of nitrogen-doped graphene thin films probed by spectroscopic ellipsometry. Thin. Solid. Films 2014, 571, 675-679. [CrossRef]

20. Chang, Y.-C.; Liu, C.-H.; Liu, C.-H.; Zhong, Z.; Norris, T.B. Extracting the complex optical conductivity of mono- and bilayer graphene by ellipsometry. Appl. Phys. Lett. 2014, 104, 261909. [CrossRef]

21. Ochoa-Martínez, E.; Gabás, M.; Barrutia, L.; Pesquera, A.; Centeno, A.; Palanco, S.; Zurutuza, A.; Algora, C. Determination of refractive index and extinction coefficient of standard production CVD-graphene. Nanoscale 2015, 7, 1491-1500. [CrossRef] [PubMed]

22. Li, W.; Cheng, G.; Liang, Y.; Tian, B.; Liang, X.; Peng, L.; Hight Walker, A.R.; Gundlach, D.J.; Nguyen, N.V. Broadband optical properties of graphene by spectroscopic ellipsometry. Carbon 2016, 99, 348-353. [CrossRef]

23. Pápa, Z.; Csontos, J.; Smausz, T.; Toth, Z.; Budai, J. Spectroscopic ellipsometric investigation of graphene and thin carbon films from the point of view of depolarization effects. Appl. Surf. Sci. 2017, 421, 714-721. [CrossRef]

24. Song, B.K.; Gu, H.G.; Zhu, S.M.; Jiang, H.; Chen, X.G.; Zhang, C.W.; Liu, S.Y. Broadband optical properties of graphene and HOPG investigated by spectroscopic Mueller matrix ellipsometry. Appl. Surf. Sci. 2018, 439, 1079-1087. [CrossRef]

25. Castriota, M.; Politano, G.G.; Vena, C.; De Santo, M.P.; Desiderio, G.; Davoli, M.; Cazzanelli, E.; Versace, C. Variable Angle Spectroscopic Ellipsometry investigation of CVD-grown monolayer graphene. Appl. Surf. Sci. 2019, 467, 213-220. [CrossRef]

26. Sun, D.; Wu, Z.K.; Divin, C.; Li, X.B.; Berger, C.; de Heer, W.A.; First, P.N.; Norris, T.B. Ultrafast Relaxation of Excited Dirac Fermions in Epitaxial Graphene. Using Optical Differential Transmission Spectroscopy. Phys. Rev. Lett. 2008, 101, 157402. [CrossRef] [PubMed]

27. Zhu, S.E.; Yuan, S.J.; Janssen, G.C.A.M. Optical transmittance of multilayer graphene. Europhys. Lett. 2012, 108, 17007. [CrossRef] 
28. Zhou, S.Y.; Gweon, G.H.; Fedorov, A.V.; First, P.N.; De Heer, W.A.; Lee, D.H.; Guinea, F.; Castro Neto, A.H.; Lanzara, A. Substrate induced bandgap opening in epitaxial graphene. Nat. Mater. 2007, 6, 770-775. [CrossRef] [PubMed]

29. Peng, X.Y.; Ahuja, R. Symmetry breaking induced bandgap in epitaxial graphene layers on SiC. Nano Lett. 2008, 8, 4464-4468. [CrossRef] [PubMed]

30. Tiwari, R.P.; Stround, D. Tunable band gap in graphene with a noncentrosymmetric superlattice potencial. Phys. Rev. B 2009, 79, 205435. [CrossRef]

31. Azadeh, M.S.S.; Kokabi, A.; Hosseini, M.; Fardmanesh, M. Tunable bandgap opening in the proposed structure of silicon-doped graphene. Micro Nano Lett. 2011, 6, 582-585. [CrossRef]

32. Das, A.; Chakraborty, B.; Sood, A.K. Raman spectroscopy of graphene on different substrates and influence of defect. Bull. Mater. Sci. 2008, 31, 579-584. [CrossRef]

33. Cancado, L.G.; Jorio, A.; Ferreira, E.H.M.; Stavale, F.; Achete, C.A.; Capaz, R.B.; Moutinho, M.V.O.; Lombardo, A.; Kulmala, T.S.; Ferrari, A.C. Quantifying Defects in Graphene via Raman Spectroscopy at Different Excitation Energies. Nano 2011, 11, 3190-3196. [CrossRef]

34. Eckmann, A.; Felten, A.; Verzhbitskiy, I.; Davey, R.; Casiraghi, C. Raman study on defective graphene: Effect of the excitation energy, type, and amount of defects. Phys. Rev. B 2013, 88, 035426. [CrossRef]

35. Enzo, C.; Oreste, D.L.; Danilo, V.; Alfonso, P.; Marco, C.; Giovanni, D.; Penelope, D.S.M.; Alfredo, A.; Angela, F.; Tania, R.; et al. Characterization of graphene grown on copper foil by chemical vapor deposition (CVD) at ambient pressure conditions. J. Raman Spectrosc. 2018, 49, 1006-1014.

36. Li, B.B.; Yu, D.P.; Zhang, S.L. Raman spectral study of silicon nanowires. Phys. Rev. B 1999, 59, 1645-1648. [CrossRef]

37. Tan, P.H.; An, L.; Liu, L.Q.; Guo, Z.X.; Czerw, R.; Carroll, D.L.; Ajayan, P.M.; Zhang, N.; Guo, H.L. Probing the phonon dispersion relations of graphite from the double-resonance process of Stokes and anti Stokes Raman scatterings in multiwalled carbon nanotubes. Phys. Rev. B 2002, 66, 245410. [CrossRef]

38. Mak, K.F.; Shan, J.; Heinz, T.F. Seeing Many-Body Effects in Single- and Few-Layer Graphene: Observation of Two-Dimensional Saddle-Point Excitons. Phys. Rev. Lett. 2011, 106, 046401. [CrossRef]

39. Yang, L.; Deslippe, J.; Park, C.-H.; Cohen, M.L.; Louie, S.G. Excitonic Effects on the Optical Response of Graphene and Bilayer Graphene. Phys. Rev. Lett. 2009, 103, 186802. [CrossRef] [PubMed]

40. Chae, D.-H.; Utikal, T.; Weisenburger, S.; Giessen, H.; von Klitzing, K.; Lippitz, M.; Smet, J. Excitonic Fano Resonance in Free-Standing Graphene. Nano Lett. 2011, 11, 1379-1382. [CrossRef] [PubMed]

41. Tropf, W.J. Temperature-dependent refractive index models for BaF2, CaF2, MgF2, SrF2, LiF, NaF, KCI, ZnS, and ZnSe. Opt. Eng. 1995, 34, 1369-1373. [CrossRef] 